\title{
Ecologists score victory over controversial dyke project
}

\section{David Cyranoski, Tokyo}

A huge land reclamation project in southwestern Japan is to be halted and partially reversed while researchers investigate its implications for marine biodiversity.

The move is seen as a significant victory for Japanese ecologists and seaweed farmers. The agriculture minister Yoshio Yatsu announced last week that the gates of a large dyke at Isahaya bay will be opened at some point while the study is done. Some ecologists believe that this will help the local marine ecosystem to recover.

Poor seaweed harvests and fishery catches led the agriculture ministry to ask an independent panel, chaired by Makoto Shimizu, a former University of Tokyo agriculturist, to look into the reclamation programme. The panel found that uncontrolled growth of diatom plankton was responsible for upsetting the ecosystem and depriving seaweed of nutrients.

Many ecologists blame the dyke, which was built in 1997 as part of a ¥249 billion (US $\$ 2$ billion) project to reclaim land around the bay for farming. The dyke created a reservoir inside the bay where sea water is purified into fresh water, a process that kills the clams and other shellfish that live in it. These shellfish would normally eat the plankton, which has since been free to grow out of control.

The panel recommends that the dyke's gates be opened during a two-year study of the dyke's effects on seaweed growth. But it suggests delaying this action for up to a year to allow for safety measures to be taken against possible adverse outcomes such as flooding.

An agriculture ministry official says that it is still "considering other hypotheses besides the dyke" as the cause of the plankton growth. These include the impact of the nearby city of Fukuoka's diversion of water for drinking from a river that feeds the bay.

But some ecologists are critical of the delay in opening the gates. "There is no time to question which factor is most important - we must try to restore the ecosystem before it is too late," says Masanori Sato of Kagoshima University's environmental science department.

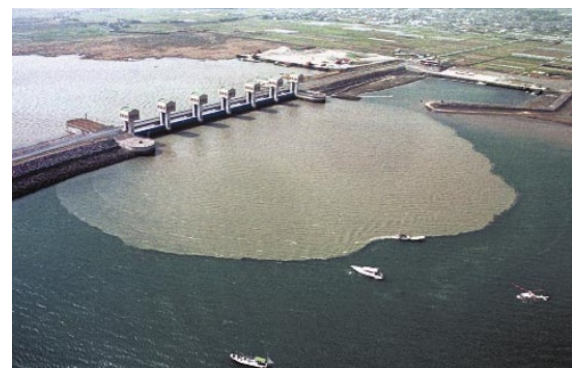

Flood of protests: the dyke at Isahaya bay has been blamed for damaging the local ecosystem.

\section{Network boost for southeast Europe}

\section{Quirin Schiermeier, Venice}

The United Nations Educational, Scientific and Cultural Organization (UNESCO) is making a move to revitalize science in southeastern Europe. It plans to help build computer networks for research and education across the region.

A meeting on scientific cooperation in southeastern Europe, held in Venice last week, identified the lack of such networks as the largest single impediment to strengthening cooperation in the area.

Pierre Lasserre, director of UNESCO's European science and technology office, said the organization would provide US $\$ 500,000$ to help buy computers and network access in the region's less-advanced countries, including Bulgaria, Romania and the fragments of the former Yugoslavian federation. UNESCO called on the European Union to provide additional financial support.

The meeting, which was co-organized by UNESCO, the Academia Europaea and the
European Science Foundation, brought together representatives from 20 European countries, including ten in southeastern Europe. Those from the southeast complained that the area's science base suffers from a lack of support from its national governments.

The situation is particularly acute in the war-torn Balkans. "In the aftermath of the war, academic life has been starved out," said Nedzad Mulabegovic, rector of the University of Sarajevo in Bosnia-Herzegovina.

Speakers also reported a severe "brain drain" from the region. Almost half of Albania's scientists left the country during the 1990s, said Tamara Eftimi, rector of Tirana Polytechnical University.

The meeting agreed that the region's best prospects lay in better access to research facilities in western Europe, particularly for the training of its young scientists. "What we need is a European training space," said Lasserre.

\section{Indian rocket fizzles out as test launch fails to fly}

\section{K. S. Jayaraman, New Delhi}

India's space science programme suffered a severe setback last week when the country's new launch rocket failed to take off on its maiden flight. The rocket, Geosynchronous Satellite Launch Vehicle (GSLV), cost 14 billion rupees (US $\$ 300$ million) to build and took ten years to develop.

Seconds after ignition, the GSLV's computer system aborted the 28 March take-off when one of the four strap-on motors in the rocket's first stage failed to develop sufficient thrust.

The aborted launch is a blow for the Indian Space Research Organisation (ISRO), which hopes that the project will end India's dependence on foreign launchers for its satellites. The ISRO also aims to gain a share of the global satellite launch business with the rocket.

These dreams are now on hold as several new systems in the GSLV, including an upper stage design imported from Russia, remain untested.

ISRO chairman Krishnaswami Kasturirangan said afterwards that failures were "normal" in the space business. He said he was happy that the safety system worked as designed and that the mission aborted before igniting the main solid booster. That would have destroyed the entire rocket and its payload, the 1,540-kilogram GSAT-1 telecommunications satellite.

One ISRO official said that the GSLV will be ready for testing again after a detailed examination of the strap-on motor. Another official said that the GSLV programme would be delayed by between six months and a year.

The failure comes at a bad time for the ISRO, which hoped that a successful GSLV launch would encourage government support for its plans for a moon mission and a satellite dedicated to astronomy.

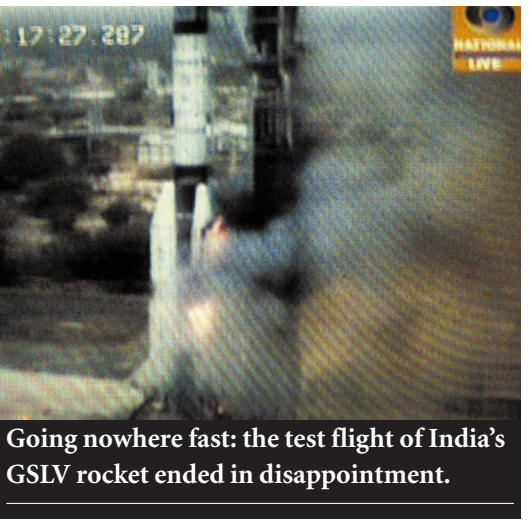

